\title{
Research Paper: Developing a Persian Verbal Fluency Test and Comparing the Results Between Healthy Persian Speakers and Persian Speakers Patients With Alzheimer Disease and Mild Cognitive Impairment
}

\author{
Ahmad Reza Khatoonabadi ${ }^{1,2}$ (D), Mahshid Aghajanzadeh ${ }^{* *}$ (D), Saman Maroufizadeh ${ }^{3}$ (D), Zahra Vahabi² ${ }^{2}$, Armin Safaeian \\ 1. Department of Speech Therapy, School of Rehabilitation, Tehran University of Medical Sciences, Tehran, Iran \\ 2. Department of Geriatric Medicine, School of Medicine, Tehran University of Medical Sciences, Tehran, Iran. \\ 3 Department of Nursing, School of Nursing and Midwifery, Guilan University of Medical Sciences, Rasht, Iran. \\ 4. Arash Women Hospital, Tehran, Iran
}

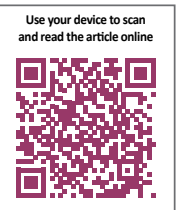

Citation Khatoonabadi AR, Aghajanzadeh M, Maroufizadeh S, Vahabi Z, Safaeian A. Developing a Persian Verbal Fluency Test and Comparing the Results Between Healthy Persian Speakers and Persian Speakers Patients With Alzheimer Disease and Mild Cognitive Impairment. Iranian Rehabilitation Journal. 2021; 19(4):387-398. http://dx.doi.org/10.32598/irj.19.4.1518.1

http://dx.doi.org/10.32598/irj.19.4.1518.1

Article info:

Received: 28 Jun 2021

Accepted: 14 Sep 2021

Available Online: 01 Dec 2021

Keywords:

Verbal fluency, Semantic, Phonemic, Alzheimer disease, Mild cognitive impairment

\section{A B STRACT}

Objectives: Phonemic and semantic fluency tasks are used for verbal fluency (VF) evaluation. The present study aimed to select the most appropriate semantic categories and the most frequent phonemes of Persian as items for the VF test. Then, we determine the test results in differentiation between cognitively intact people and those with Mild Cognitive Impairment (MCI) and Alzheimer Disease (AD).

Methods: A cross-sectional study was conducted on 120 people (60 cognitively intact, 30 with $\mathrm{AD}$, and 30 with $\mathrm{MCI}$ ) in two phases. In phase one, linguists determine the most frequent phonemes at the beginning of Persian words and the most frequent semantic categories based on a survey. In phase two, the verbal fluency test was administered to cognitively intact people and those with cognitive impairment (patients with $\mathrm{AD}$ and $\mathrm{MCI}$ ). One-way ANOVA and multiple linear regression were used for statistical analysis.

Results: The normal subjects scored significantly higher in all phonemic and semantic fluency tasks than the patients with $\mathrm{AD}$ and people with $\mathrm{MCI}(\mathrm{P}<0.05)$. Regarding the phonemic VF task, the phonemes $/ \mathrm{sh} /, / \mathrm{s} /$, and then $/ \mathrm{a} /$ were better in differentiating the $\mathrm{MCI}$ and $\mathrm{AD}$ groups from the normal group. Regarding the semantic VF task, the animals' category was better differentiated the $\mathrm{MCI}$ and $\mathrm{AD}$ groups from the normal group.

Discussion: Comparing frequent phonemes and semantic categories of Persian across three groups of normal, $\mathrm{AD}$, and $\mathrm{MCI}$ showed that some phonemes and semantic categories can be more differentiating in the VF task. However, it is a preliminary validation study, and this topic needs more investigation in the future.

\section{* Corresponding Author:}




\section{Highlights}

- In differentiating MCI and $\mathrm{AD}$, the semantic VF test is more efficient than the phonemic VF test.

- The VF score had a significantly positive correlation with MMSE scores.

- In semantic VF, animals' semantic category better differentiated the MCI and AD groups from the normal group.

- In phonemic $\mathrm{VF}$, the /sh/,/s/ phonemes, and then /a/ better differentiate the $\mathrm{MCI}$ and $\mathrm{AD}$ groups from the normal group.

\section{Plain Language Summary}

Alzheimer Disease (AD) and dementia are the most prevalent disease among aging population. To screen and determine the severity cognitive evaluation instruments are often used. VF is one of the instruments used in clinical and research to detect cognitive changes based on word retrieval, which are two types: the phonemic VF and the semantic VF. We concluded that comparing frequent phonemes and semantic categories across three groups of normal, AD, and MCI some phonemes and semantic categories can be more differentiating in the VF task.

\section{Introduction}

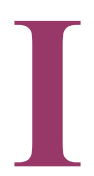

$\mathrm{n}$ recent decades, the aging population worldwide has accompanied with an increase in some related disorders, such as cognitive impairments. Alzheimer Disease $(\mathrm{AD})$ is the most prevalent form of cognitive impairment, constituting 50\%-70\% of the cases of dementia [1]. Mild Cognitive Impairment (MCI) is the term applied to a condition during which older people with a subjective cognitive complaint have objective memory impairment within the absence of purposeful incapacity [2-4]. The conversion of MCI to AD is $10 \%-15 \%$ annually $[5,6]$.

Cognitive evaluation instruments are often used for screening, differential diagnosis, determination of disease severity, and examining disease progression in patients [7]. Verbal Fluency (VF) is one of the instruments most commonly used in clinical and research to detect cognitive changes based on word retrieval. Among the tasks used for assessing word retrieval, the VF test is a suitable index sensitive to brain dysfunctions [8]. Thurstone developed a VF test comprising noun retrieval starting with phoneme $/ \mathrm{c} /$ and $/ \mathrm{s} /$ in writing for 5 minutes in a normal group [9]. Since then, VF has become an extensively-used instrument in clinical research and interventions to evaluate cognitive status [10]. In a VF test, individuals are usually instructed to generate numerous words within a time frame.

Two types are associated with VF tests: the phonemic VF, where subjects must generate words that start with a specific phoneme, and the semantic VF, where a person has to produce words from a given semantic class [11] Usually, each test requires the participant to complete the task within 60 seconds [12].

Different categories and phonemes can be used to examine semantic and phonological fluency: the most frequently used ones are naming fruits and animals to evaluate semantic fluency and naming words that begin with /f/, /a:/, and /s/ [13]. The use of /f/, /a:/, and /s/ phonemes in the original version of the VF test is based on the higher frequency of these phonemes and their ease in English [14]. Interestingly, when transferring these criteria to the case of Portuguese speakers, Senhorini et al. found that /f/, /a:/, and /p/ phonemes are among the frequent phonemes of Portuguese, and when the test was administered in its original format, comparable results between English and Portuguese speakers were obtained [15].

In Portuguese, the $/ \mathrm{s} /$ phoneme includes the homophone form of /c/ before "e" and "I", which may be a source of confusion. Moreover, the $/ \mathrm{p} /$ phoneme is frequent in Portuguese. Therefore, in the study by Steiner, the $\mathrm{f} / \mathrm{a} / \mathrm{p}$ format was compared with the $\mathrm{f} / \mathrm{a} / \mathrm{s}$ format; both $\mathrm{f} / \mathrm{a} / \mathrm{p}$ and $\mathrm{f} / \mathrm{a} / \mathrm{s}$ were examined. In other words, these two versions could be used interchangeably [14]. Borkowski et al. [16] evaluated 24 phonemes of the English language and divided them based on the level of difficulty into three categories: easy (H, D, M, W, A, B, F, P, T, C, S), moderate (I, O, N, E, G, L, R), and problematic (Q, J, V, Y, K, U). In different languages, the main question is what phonemes and categories are the best for use in VF tasks. 
Various studies have investigated the effects of sex, age, bilingualism, and education level on VF. Research has shown that sex does not affect people's performance on the VF task $[17,18]$. Studies have also indicated that age mainly affects people's performance on semantic and phonological VF tasks. In other words, as age increases, people's performance on the VF task is reduced $[19,20]$. Besides, the level of education, similar to age, considerably affects people's performance [17]. Troyer et al. found that VF is affected by age and education, but not by sex [13]. In a study on the Brazilian population, it was found that the level of education markedly affects $\mathrm{VF}$, and different cutoff scores must be considered based on the level of education in different populations [21].

One of the most important items in verbal fluency is bilingualism. Verbal fluency research on bilingual and monolingual execution has shown mixed outcomes [2225]. Regarding language and cultural differences, research has demonstrated that performance on VF tasks is affected by language and culture. Overall, studies have shown that VF tasks' normative data for English-speaking people cannot be used for those whose first language is not English [19].

For Persian speakers, VF tasks are administered with the same phonemes and semantic categories as those selected in English [26]. In other words, It is administered without considering the difference in the frequency of phonemes or semantic categories in terms of exposure and use in Persian, and precisely the same English items are used $[27,28]$. So far, no in-depth study has been performed based on the features of the Persian language. Because the most frequent usage of the VF test is in cognitive assessments to distinguish normal from cognitively impaired participants, the present study has two purposes. The primary goal was to select the most appropriate semantic categories and the most frequent phonemes of Persian as items in the VF task. The secondary objective was to determine the results of these tests in cognitively intact people and those with cognitive impairment (MCI and AD) to determine the test's power in differentiating cognitively intact people from those with cognitive impairment.

\section{Materials and Methods}

\section{Study participants}

The participants were 120 people, according to similar studies in this area and terms of normal distribution (60 cognitively intact, 30 with $\mathrm{AD}$, and 30 with $\mathrm{MCI}$ ). The individuals with cognitive impairment (AD and $\mathrm{MCI}$ ) were selected by convenience sampling method from those visiting a particular hospital for psychiatry disorders (Roozbeh Hospital, Tehran City, Iran) from January 2019 to January 2020. The control group consisted of 60 community-dwelling volunteers. Participants in the present study included monolingual and bilingual individuals. The first language of bilingual participants was Persian.

MCI patients were evaluated by a cognitive neurologist and met the clinical Petersen's criteria [6]. Patients with AD were diagnosed according to having MMSE $<22$ (mini-mental state exam) [29], evidence of MRI, and questions regarding functional activities. The participants were aged between 60 and 80 years, and their Mean \pm SD age was $74.32 \pm 9.41$ years in the control group, $74.47 \pm 8.80$ years in the group with $\mathrm{AD}$, and $75.07 \pm 7.94$ years in the group with MCI. All patients in the group with MCI were in the early stages of diagnosis. All participants were native Persian speakers. They gave written informed consent for the study participation.

\section{Study design}

The research was an analytical cross-sectional study. The inclusion criteria for the cognitively intact people were as follows: no history of recent cognitive disorders, mostly episodic memory, MMSE $>24$, interview with subject and his/her informant, informal executive function test such as Luria 3-step test (all done by a cognitive neurologist). The inclusion criteria for moderate dementia due to $\mathrm{AD}$ were as follows: having general cognitive impairments (MMSE<24), having signs of brain pathology in MRI (using MTA scale and Fazekas scale to exclude the vascular changes) [30,31], having problems in daily activities, lacking motor disorders, history of brain damage or stroke, lacking received cognitive or linguistic treatments from a speech therapist.

The inclusion criteria for MCI were as follows: intact daily activities, having problems in executive functions using informal Luria 3-step test, informal episodic memory test, interview with the informant, and finally cognitive neurologist's confirmation. In this study, because VF performance for differentiating phonemes with different written forms needs a minimum primary school education level, this level of education was considered an inclusion criterion. The participants' educational background was expressed on a scale from primary (3 to 6 years), secondary (6 to 12 years) to university. In addition to examining the history of diseases and the person's cognitive status using his/her medical records, MMSE [7] was first administered to all the participants. The age, sex, being bilingual or monolingual, and level of education of the 
Table 1. Demographic and clinical characteristics of the study groups

\begin{tabular}{|c|c|c|c|c|c|}
\hline \multirow{2}{*}{ Variables } & \multicolumn{3}{|c|}{ Mean $\pm S D$} & \multirow{2}{*}{ F Statistics or $\chi^{2}$} & \multirow{2}{*}{$\mathbf{P}$} \\
\hline & Normal & $\mathrm{MCl}$ & $A D$ & & \\
\hline Age (y) & $74.32 \pm 9.41$ & $75.07 \pm 7.94$ & $74.47 \pm 8.80$ & 0.07 & 0.930 \\
\hline Sex & & & & 1.37 & 0.504 \\
\hline Male & $27 \pm 45.0$ & $17 \pm 56.7$ & $13 \pm 43.3$ & & \\
\hline Female & $33 \pm 55.0$ & $13 \pm 43.3$ & $17 \pm 56.7$ & & \\
\hline Level of Education & & & & 6.06 & 0.195 \\
\hline Primary & $47 \pm 78.3$ & $27 \pm 90.0$ & $24 \pm 80.0$ & & \\
\hline Secondary & $9 \pm 15.0$ & $0 \pm 0$ & $5 \pm 16.7$ & & \\
\hline University & $4 \pm 6.7$ & $3 \pm 10.0$ & $1 \pm 3.3$ & & \\
\hline Language mode & & & & 4.31 & 0.116 \\
\hline Monolingual & $20 \pm 33.3$ & $4 \pm 13.3$ & $7 \pm 23.3$ & & \\
\hline Bilingual & $40 \pm 66.7$ & $26 \pm 86.7$ & $23 \pm 76.7$ & & \\
\hline MMSE & $25.70 \pm 2.36$ & $21.10 \pm 1.47$ & $15.20 \pm 2.19$ & 246.34 & $<0.001$ \\
\hline
\end{tabular}

MCI: mild cognitive impairment; AD: Alzheimer disease; MMSE: mini-mental state examination.

Continuous variables are expressed as Mean $\pm \mathrm{SD}$ and categorical variables as frequency (\%).

participants were recorded. In bilingual participants, their first language was Persian. The participants were asked to produce as quickly as possible the nouns starting with the specified phonemes in 60 seconds as for phonological VF. As for semantic VF, they were asked to name words that belong to each category in the same order.

\section{Study procedure}

The present study consisted of two phases. Because the frequency of phonemes and categories are different in terms of culture and language, in the first phase, besides existent phonemes in the current verbal fluency test (f, a, and s), most frequent phonemes (ǽ, sh, k, m, b, r, $\mathrm{p}, \mathrm{t}, \mathrm{d})$ at the beginning of Persian words were selected from the contemporary Farsi dictionary. For semantic category, some categories such as animals, fruits, and objects categories, as well as common categories such as kitchenware, household, body part, city, and colors, were selected from a pilot study on normal participants of 40 60 years old. Afterward, an expert panel consisting of three speech and language pathologists in the cognitive field and three linguists in the cognitive-linguistic field, experimental phonemes, and categories were confirmed and finalized. Final items included /a/, /ǽ/, /s/, /sh/, /k/,
$/ \mathrm{m} /$, and $/ \mathrm{b} /$ in phonemes and animal, fruit, object, body part, and city in semantic categories.

In the second phase, the VF test was administered to cognitively intact people and those with cognitive impairment (AD and MCI groups). The semantic category selected in the first phase was used to examine semantic VF. The participants were asked to mention as many words as possible from one of the categories in 60 seconds. The test was repeated for the following categories until all the categories were covered. For phonological VF, the participants were requested to produce as many words as possible, beginning with a specified phoneme in 60 seconds. This procedure was repeated for the rest of the phonemes until the test ended. The number of words produced was recorded as the score for all categories and phonemes.

\section{Statistical analysis}

In this study, continuous variables were presented as Mean \pm SD and categorical variables as number (\%). We used the 1-way ANOVA and the Chi-square test to compare baseline characteristics between groups. Also, 1-way ANOVA was used to compare three study groups regarding the VF and its components. In univariate analysis, the relationships between demographic characteristics and VF were examined using the Pearson correlation coef- 
Table 2. Differences between study groups on verbal fluency

\begin{tabular}{|c|c|c|c|c|c|c|c|c|}
\hline \multirow{3}{*}{ Type of Test } & \multirow{3}{*}{ Test items } & \multicolumn{3}{|c|}{ Mean \pm SD } & \multirow{3}{*}{$F_{(2,117)}$} & \multirow{3}{*}{$\mathbf{P}$} & \multirow{3}{*}{$\begin{array}{l}\text { Effect Size } \\
\quad \text { (Eta } \\
\text { Squared) }\end{array}$} & \multirow{3}{*}{$\begin{array}{l}\text { Pairwise } \\
\text { Signifi- } \\
\text { cance Dif- } \\
\text { ferences }\end{array}$} \\
\hline & & & Group & & & & & \\
\hline & & Normal & $\mathrm{MCl}$ & $A D$ & & & & \\
\hline \multirow{8}{*}{$\begin{array}{c}\text { Phonemic } \\
\text { Fluency }\end{array}$} & $a$ & $8.07 \pm 3.64$ & $4.93 \pm 2.20$ & $3.50 \pm 1.33$ & 28.59 & $<0.001$ & 0.328 & $\begin{array}{c}\text { Normal } \\
>\mathrm{MCl}=\mathrm{AD}\end{array}$ \\
\hline & @ & $7.05 \pm 3.24$ & $3.67 \pm 1.81$ & $3.50 \pm 1.59$ & 26.83 & $<0.001$ & 0.314 & $\begin{array}{c}\text { Normal } \\
>\mathrm{MCl}=\mathrm{AD}\end{array}$ \\
\hline & $\mathrm{s}$ & $11.60 \pm 3.71$ & $5.67 \pm 2.48$ & $4.87 \pm 1.87$ & 65.07 & $<0.001$ & 0.527 & $\begin{array}{c}\text { Normal } \\
>\mathrm{MCl}=\mathrm{AD}\end{array}$ \\
\hline & sh & $9.32 \pm 3.13$ & $4.90 \pm 1.81$ & $4.67 \pm 1.86$ & 46.64 & $<0.001$ & 0.444 & $\begin{array}{c}\text { Normal } \\
>\mathrm{MCl}=\mathrm{AD}\end{array}$ \\
\hline & k & $8.30 \pm 3.51$ & $5.37 \pm 2.24$ & $4.17 \pm 1.34$ & 25.09 & $<0.001$ & 0.300 & $\begin{array}{c}\text { Normal } \\
>\mathrm{MCl}=\mathrm{AD}\end{array}$ \\
\hline & $\mathrm{m}$ & $8.70 \pm 3.81$ & $5.47 \pm 1.94$ & $4.57 \pm 2.18$ & 22.26 & $<0.001$ & 0.276 & $\begin{array}{c}\text { Normal } \\
>\mathrm{MCl}=\mathrm{AD}\end{array}$ \\
\hline & $\mathrm{b}$ & $7.98 \pm 3.50$ & $5.53 \pm 2.21$ & $5.27 \pm 2.29$ & 11.59 & $<0.001$ & 0.165 & $\begin{array}{c}\text { Normal } \\
>\mathrm{MCl}=\mathrm{AD}\end{array}$ \\
\hline & Total Score & $61.02 \pm 15.76$ & $35.53 \pm 10.83$ & $30.53 \pm 6.08$ & 72.97 & $<0.001$ & 0.555 & $\begin{array}{c}\text { Normal } \\
>\mathrm{MCl}=\mathrm{AD}\end{array}$ \\
\hline \multirow{5}{*}{$\begin{array}{c}\text { Semantic } \\
\text { Fluency }\end{array}$} & Animal & $13.10 \pm 4.41$ & $5.83 \pm 2.79$ & $5.17 \pm 2.15$ & 67.58 & $<0.001$ & 0.536 & $\begin{array}{c}\text { Normal } \\
>\mathrm{MCl}=\mathrm{AD}\end{array}$ \\
\hline & Fruit & $13.03 \pm 3.06$ & $10.07 \pm 2.73$ & $5.93 \pm 2.05$ & 66.68 & $<0.001$ & 0.533 & $\begin{array}{c}\text { Normal } \\
>\mathrm{MCl}>\mathrm{AD}\end{array}$ \\
\hline & Object & $15.03 \pm 4.33$ & $9.97 \pm 3.47$ & $6.93 \pm 2.13$ & 52.96 & $<0.001$ & 0.475 & $\begin{array}{c}\text { Normal } \\
>\mathrm{MCl}>\mathrm{AD}\end{array}$ \\
\hline & Body Part & $13.93 \pm 3.99$ & $10.83 \pm 2.96$ & $6.10 \pm 2.35$ & 53.23 & $<0.001$ & 0.476 & $\begin{array}{c}\text { Normal } \\
>\mathrm{MCl}>\mathrm{AD}\end{array}$ \\
\hline & City & $13.20 \pm 4.23$ & $9.37 \pm 2.87$ & $5.30 \pm 2.23$ & 51.99 & $<0.001$ & 0.471 & $\begin{array}{c}\text { Normal } \\
>\mathrm{MCl}>\mathrm{AD}\end{array}$ \\
\hline Verbal Fluency & Total Score & $129.32 \pm 28.28$ & $81.60 \pm 18.48$ & $59.97 \pm 10.38$ & 106.66 & $<0.001$ & 0.646 & $\begin{array}{c}\text { Normal } \\
>\mathrm{MCl}>\mathrm{AD}\end{array}$ \\
\hline
\end{tabular}

MCI: mild cognitive impairment; AD: Alzheimer disease.

Iranian Rehabilitation Dourna

ficient, independent t-test, and 1-way ANOVA. Finally, multiple linear regression analysis was used to explore the relationship between VF and demographic variables. Data analysis was carried out using SPSS for Windows, v. 16 (SPSS Inc., Chicago, IL, USA). All statistical tests were 2-sided, and the level of significance was set at 0.05 .

\section{Results}

\section{Characteristics of the study groups}

The demographic characteristics of the participants are summarized in Table 1. There were no significant differences in age $(\mathrm{P}=0.930)$, sex $(\mathrm{P}=0.504)$, level of education $(\mathrm{P}=0.195)$, and bilingualism $(\mathrm{P}=0.116)$ between the three study groups.
Comparing verbal fluency between study groups

\section{Phonemic fluency}

As presented in Table 2, the normal subjects scored significantly higher in all letter/phonemic fluency tasks than the patients with $\mathrm{AD}$ and those with MCI. Also, there were no significant differences between patients with $\mathrm{AD}$ and patients with MCI on all letter/phonemic fluency tasks. The highest effect size was obtained for the $/ \mathrm{s} /$ and $/ \mathrm{sh} /$ phonemic fluency tasks $\left(\eta^{2}=0.527, \eta^{2}=0.444\right.$, respectively), and the lowest in the $/ b /$ phonemic fluency $\operatorname{task}\left(\eta^{2}=0.165\right)$.

\section{Semantic fluency}

The healthy subjects scored significantly higher in all semantic fluency tasks than the patients with $\mathrm{AD}$ and those with MCI. Also, the patients with MCI scored significantly higher for all semantic fluency tasks than the patients with AD, except for the task "animal." The highest effect size was obtained for the "animal" and "fruit" 
Table 3. Relationship of demographic variables with verbal fluency in the total population $(n=120)$

\begin{tabular}{|c|c|c|c|c|c|c|}
\hline \multirow{2}{*}{ Variables } & \multicolumn{6}{|c|}{ Mean \pm SD or $r$} \\
\hline & Phonemic Fluency & $\mathbf{P}$ & Semantic Fluency & $\mathbf{P}$ & Verbal Fluency & $\mathbf{P}$ \\
\hline Age & -0.209 & 0.022 & -0.315 & $<0.001$ & -0.276 & 0.002 \\
\hline Sex & & 0.920 & & 0.580 & & 0.803 \\
\hline Male & $47.21 \pm 19.40$ & & $51.93 \pm 19.49$ & & 99.1437 .44 & \\
\hline Female & $46.86 \pm 18.80$ & & $54.02 \pm 21.49$ & & $100.87 \pm 38.41$ & \\
\hline Education & & 0.222 & & 0.127 & & 0.149 \\
\hline Primary & $45.60 \pm 18.09$ & & $51.37 \pm 18.33$ & & $96.97 \pm 34.46$ & \\
\hline Secondary & $52.86 \pm 21.69$ & & $57.79 \pm 26.10$ & & $110.64 \pm 46.86$ & \\
\hline University & $54.25 \pm 24.07$ & & $65.00 \pm 31.28$ & & $119.25 \pm 54.58$ & \\
\hline Language mode & & 0.050 & & 0.103 & & 0.062 \\
\hline Monolingual & $52.77 \pm 22.70$ & & $58.19 \pm 25.05$ & & $110.97 \pm 46.45$ & \\
\hline Bilingual & $45.02 \pm 17.24$ & & $51.22 \pm 18.49$ & & $96.25 \pm 33.76$ & \\
\hline MMSE & 0.659 & $<0.001$ & 0.799 & $<0.001$ & 0.765 & $<0.001$ \\
\hline
\end{tabular}

semantic fluency tasks $\left(\eta^{2}=0.536, \eta 2=0.533\right.$, respectively). Contrary to the phonemic fluency scores, patients with $\mathrm{AD}$ obtained lower semantic fluency scores than patients with MCI.

\section{Verbal fluency and demographic characteristics}

Table 3 presents the relationships of VF with demographic/cognitive characteristics in the study participants. As seen in Table 3, significant but low negative correlations were obtained between age and scores of verbal, phonemic, and semantic fluency $(r=-0.276, r=-$

Table 4. Relationship of demographic variables with verbal fluency in the total population $(n=120)$

\begin{tabular}{|c|c|c|c|c|c|c|c|}
\hline \multirow{2}{*}{\multicolumn{2}{|c|}{ Variables }} & \multicolumn{2}{|c|}{ Phonemic Fluency } & \multicolumn{2}{|c|}{ Semantic Fluency } & \multicolumn{2}{|c|}{ Verbal Fluency } \\
\hline & & b (SE) & $\mathbf{P}$ & b (SE) & $\mathbf{P}$ & b (SE) & $\mathbf{P}$ \\
\hline \multicolumn{2}{|c|}{ Age } & $-0.39(0.13)$ & 0.003 & $-0.66(0.11)$ & $<0.001$ & $-1.05(0.22)$ & $<0.001$ \\
\hline Sex & $\begin{array}{l}\text { Female vs } \\
\text { Male }\end{array}$ & $-2.03(2.29)$ & 0.377 & $0.78(1.98)$ & 0.696 & $-1.25(3.79)$ & 0.742 \\
\hline \multirow{2}{*}{ Education } & $\begin{array}{l}\text { Secondary vs } \\
\text { Primary }\end{array}$ & $2.80(3.62)$ & 0.441 & $2.75(3.13)$ & 0.382 & $5.55(6.00)$ & 0.357 \\
\hline & $\begin{array}{l}\text { University vs } \\
\text { Primary }\end{array}$ & $5.00(4.62)$ & 0.282 & $7.54(4.00)$ & 0.062 & $12.54(7.66)$ & 0.104 \\
\hline $\begin{array}{l}\text { Language } \\
\text { mode }\end{array}$ & $\begin{array}{l}\text { Bilingual vs } \\
\text { Monolingual }\end{array}$ & $-2.65(2.62)$ & 0.313 & $-2.01(2.27)$ & 0.378 & $-4.66(4.34)$ & 0.285 \\
\hline \multirow{2}{*}{ Group } & $\begin{array}{l}\mathrm{MCl} \text { vs Nor- } \\
\text { mal }\end{array}$ & $-24.64(2.87)$ & $<0.001$ & $-21.09(2.48)$ & $<0.001$ & $-45.73(4.75)$ & $<0.001$ \\
\hline & AD vs Normal & $-30.01(2.77)$ & $<0.001$ & $-38.37(2.40)$ & $<0.001$ & $-68.73(4.59)$ & $<0.001$ \\
\hline
\end{tabular}

MCI: mild cognitive impairment; $\mathrm{AD}$ : Alzheimer disease; SE, standard error.

Iranian Rehabilitation Journal

$\mathrm{b}$ is the unstandardized regression coefficient. 
Table 5. Diagnostic accuracy of both phonemic and semantic fluency tasks for detecting patients with $\mathrm{MCI}$ and or AD using area under the ROC curve (AUC)

\begin{tabular}{|c|c|c|c|c|c|}
\hline \multirow{2}{*}{ Variables } & \multirow{2}{*}{ Items } & \multicolumn{4}{|c|}{ Area under the ROC curve (AUC) } \\
\hline & & AD vs Normal & $\mathrm{MCl}$ vs Normal & $\mathrm{AD}$ vs $\mathrm{MCl}$ & $\mathrm{MCl}+\mathrm{AD}$ vs Normal \\
\hline \multirow{7}{*}{$\begin{array}{c}\text { Phonemic Fluency } \\
\text { Task }\end{array}$} & a & 0.913 & 0.779 & 0.711 & 0.846 \\
\hline & $@$ & 0.844 & 0.828 & 0.520 & 0.836 \\
\hline & s & 0.949 & 0.903 & 0.598 & 0.926 \\
\hline & sh & 0.907 & 0.896 & 0.528 & 0.902 \\
\hline & k & 0.844 & 0.738 & 0.663 & 0.791 \\
\hline & $\mathrm{m}$ & 0.831 & 0.765 & 0.637 & 0.798 \\
\hline & b & 0.729 & 0.710 & 0.524 & 0.720 \\
\hline \multirow{5}{*}{$\begin{array}{c}\text { Semantic Fluency } \\
\text { Task }\end{array}$} & Animal & 0.948 & 0.918 & 0.553 & 0.933 \\
\hline & Fruit & 0.973 & 0.761 & 0.894 & 0.867 \\
\hline & bject & 0.979 & 0.824 & 0.762 & 0.902 \\
\hline & Body Part & 0.977 & 0.739 & 0.914 & 0.858 \\
\hline & City & 0.973 & 0.775 & 0.864 & 0.874 \\
\hline \multirow{3}{*}{ Total Score } & Phonemic Fluency & 0.974 & 0.925 & 0.629 & 0.949 \\
\hline & Semantic Fluency & 1.000 & 0.909 & 0.919 & 0.955 \\
\hline & Verbal Fluency & 1.000 & 0.949 & 0.850 & 0.974 \\
\hline
\end{tabular}

MCI: Mild Cognitive Impairment; AD: Alzheimer disease; ROC: receiver operating characteristic curve.

Mranian Rehabilitation Dourna

0.209 , and $\mathrm{r}=-0.315$, respectively). There were no sex differences in verbal $(\mathrm{P}=0.803)$, phonemic $(\mathrm{P}=0.920)$, and semantic fluency $(\mathrm{P}=0.580)$. The mean VF in bilinguals was lower than monolinguals, although the difference was not statistically significant $(\mathrm{P}=0.062)$. The same results were also obtained for phonemic and semantic fluency $(\mathrm{P}=0.050$ and $\mathrm{P}=0.103$, respectively). As expected, the $\mathrm{VF}$ was positively and strongly correlated with MMSE ( $\mathrm{r}=0.765$, $\mathrm{P}<0.001)$. The same results were also obtained for phonemic and semantic fluency (Table 3).

According to multiple linear regression analysis, age was significantly and negatively correlated with verbal $(b=-1.05$, $\mathrm{P}<0.001)$, phonemic $(\mathrm{b}=-0.39, \mathrm{P}=0.003)$, and semantic fluency $(b=-0.66, P<0.001)$. In other words, one year increase in age was associated with $1.05,0.39,0.66$ points decrease in verbal, phonemic, and semantic fluency, respectively. Sex, level of education, and bilingualism were not related to scores of verbal, phonemic, and semantic fluency.

After adjusting for demographic variables, patients with MCI obtained lower scores in verbal $(b=-45.73, \mathrm{P}<0.001)$, phonemic $(b=-24.64, P<0.001)$, and semantic fluency $(b=$ 21.09, $\mathrm{P}<0.001)$ than normal subjects. Patients with $\mathrm{AD}$ also obtained lower scores in verbal $(b=-68.73, P<0.001)$, phonemic $(b=-30.01, P<0.001)$, and semantic fluency $(b=$ 38.37, $\mathrm{P}<0.001)$ than normal subjects. As expected, the VF was positively and strongly correlated with MMSE $(\mathrm{r}=0.765, \mathrm{P}<0.001)$. The same results were also obtained for phonemic and semantic fluency (Table 3).

ROC (receiver operating characteristic curve) curve analysis

Based on the AUC (Area Under the ROC Curve) values, the phonemic fluency tasks with the highest diagnostic value were/s/ followed by $/ \mathrm{sh} /$ and /a/ phonemes in differentiating between patients with $\mathrm{MCI} / \mathrm{AD}$ and normal subjects (Table 4). Amongst the semantic fluency tasks, "animals" had the highest diagnostic accuracy in classifying patients with $\mathrm{MCI} / \mathrm{AD}$ versus normal controls (Table 5). 


\section{Discussion}

This study aimed to find the most frequent initial phonemes and semantic categories in the Persian language and culture as items for the VF test. Then, we examined the scores of the selected items in the phonological and semantic VF tests belonging to cognitively intact individuals compared to those with $\mathrm{AD}$ and $\mathrm{MCI}$.

Results showed that the healthy group had a higher phonemic fluency score than the $\mathrm{AD}$ and $\mathrm{MCI}$ groups. Also, there was generally no difference between $\mathrm{AD}$ and $\mathrm{MCI}$ in terms of phonemic scores. Therefore, the selected phonemes for the VF test can properly differentiate people with cognitive impairment from cognitively intact people, but they do not differentiate between MCI and $\mathrm{AD}$. This finding is consistent with other studies reporting that the VF test is appropriate for assessing people's cognitive level [32-34].

In the present study, normal people scored higher than $\mathrm{AD}$ and $\mathrm{MCI}$ groups on the semantic fluency task. Contrary to the phonemic fluency score, which did not show any difference between $\mathrm{AD}$ and $\mathrm{MCI}$, the $\mathrm{AD}$ group scored lower in the semantic fluency score than the MCI group, except for the "animal" category. Thus, the semantic fluency task would differentiate these two cognitive impairments groups. Based on previous studies, VF test values are markedly decreased insomuch as 9 years before the onset of dementia [35]. It has also been shown that $\mathrm{VF}$ is sensitive in differentiating the normal group from those with $\mathrm{AD}$ and $\mathrm{MCI}$ [36]. Findings of the present study show that, in differentiating $\mathrm{MCI}$ and $\mathrm{AD}$, the semantic VF test is more efficient than the phonemic VF test. This result is in line with that of other studies which report that the semantic VF test has clinical application in predicting the progression from $\mathrm{MCI}$ to $\mathrm{AD}$ [35-37]. Other studies also report evidence for the higher speed of reduced semantic fluency than phonemic fluency in people with $\mathrm{AD}[38,39]$.

There is a significantly negative correlation between age and VF scores in middle age and higher age, whether semantic or phonemic. That is, as age increases, VF scores are reduced. Based on the literature, it is likely that as age increases, the cognitive ability would be reduced; this result is in line with the findings of other studies [19, 40, 41].

So far, the results of studies on the effect of sex on VF scores have been very different. In the present study, there is no difference in VF score between the two sexes, and this result is consistent with the result of some studies $[19,40,42,43]$ while it differs from others $[44,45]$.

Moreover, no significant difference was observed between the level of education and VF scores in this study. Previous studies have reported different results in this regard. Kawano et al. concluded that the number of years of education affects the category fluency test score but does not significantly affect the phonemic fluency test score [46]. Many studies report that education influences VF scores [33, 40, 47, 48]. The difference in the present research results and other studies on the effect of education on VF score may result from the fact that the majority of our participants had a primary school level education, with very few people having higher levels of education. Therefore, the effect of education could not be well examined.

Although no significant difference was found between monolinguals and bilinguals in terms of VF score, in general, bilinguals obtained lower scores compared to monolinguals. This result is in line with that of most studies [49-51]. These results showed that switching in bilingual patients takes a specific time and is slower than monolinguals in performing the task. Some studies also note that bilingual participants produce fewer responses than monolinguals and obtain lower scores on the VF task $[25,52]$. Perhaps these different results are due to differences in proficiency and use of the second language in participants.

The VF score had a significantly positive correlation with MMSE scores. It means that the VF scores resulting from the items selected in this study are consistent with valid cognitive tests, and the selected items can demonstrate cognitive impairment. According to McDonnell et al., the results of their study support the hypothesis that semantic fluency adds considerable predictive value to the MMSE [53]. The results of multiple linear regression analysis more precisely show the relationship between age and VF score. Also, after adjusting for the demographic variables, the $\mathrm{AD}$ and $\mathrm{MCI}$ groups still had lower VF task scores.

ROC curve analysis results show that, in phonemic VF, the $/ \mathrm{sh} /, \mathrm{s} / \mathrm{phonemes}$, and then $/ \mathrm{a} /$ better differentiate the $\mathrm{MCI}$ and $\mathrm{AD}$ groups from the normal group. The result of remaining /sh/ in phonemic $\mathrm{VF}$ is that $/ \mathrm{sh} /$ is more frequent in Persian than in English. On the other hand, the frequencies of consonants are very similar between English and Persian [54]. In semantic VF, animals' semantic category better differentiated the $\mathrm{MCI}$ and $\mathrm{AD}$ groups from the normal group. Therefore, the phonemes 
and semantic categories with a higher power in differentiating the normal group from $\mathrm{AD}$ and $\mathrm{MCI}$ groups are primarily consistent with other studies' results. One reason why the category of animals has mainly been used in verbal frequency tests is that people learn this category during childhood. Therefore most people have similar information when it comes to this category [12, 13]. Phonological fluency tasks are language-dependent due to the different frequencies of phonemes in different languages. A review of the literature reveals that the most frequently used category in semantic VF tasks is animals. Moreover, the culture, values of the society, and the types of interaction affect categories sensitive to cognitive changes [17].

\section{Conclusion}

The comparison of frequent phonemes and semantic categories of Persian across the three groups of normal, $\mathrm{AD}$, and MCI showed that the phonemes $/ \mathrm{sh} /, / \mathrm{s} /$, and then /a/, as well as the semantic category of animals, can properly differentiate between normal people and those with cognitive impairment. Therefore, these items can be used in addition to other cognitive tests for determining cognitive impairment. The limitation of this was the low level of education in participants that affected cognitive test scores, and low scores were obtained. This study can be considered as a preliminary validated study, and the cutoffs in the VF task for identifying the MCI and dementia patients should not be used in clinical practice.

\section{Ethical Considerations}

\section{Compliance with ethical guidelines}

This study was approved by the Ethics Committee of Tehran University of Medical Sciences, Tehran (Registration No.: IR.TUMS.VCR.REC.1396.4737). The signed informed consent was obtained from all participants.

\section{Funding}

This study was funded and supported by Tehran University of Medical Sciences (Grant No.: 96-03-206-36188).

\section{Authors' contributions}

Conceptualization and supervision: Mahshid Aghajanzadeh and Ahmad Reza Khatoonabadi; Methodology: Mahshid Aghajanzadeh and Ahmad Reza Khatoonabadi and Zahra Vahabi; Data collection: Armin Safaeian; Data analysis: Saman Maroufizadeh; Writing -original draft: All authors.

\section{Conflict of interest}

The authors declared no conflict of interest.

\section{Acknowledgments}

We thank patients and healthy subjects for participating in the study and Tehran University of Medical Sciences for their friendly cooperation in data collection.

\section{References}

[1] Alzheimer's Disease International. World Alzheimer Report. The Global Impact of Dementia; 2015. https://www. alzint.org/u/worldalzheimerreport2015summary.pdf

[2] Kabani NJ, Sled JG, Shuper A, Chertkow H. Regional magnetization transfer ratio changes in mild cognitive impairment. Magnetic Resonance in Medicine. 2002; 47(1):143-8. [DOI:10.1002/mrm.10028] [PMID]

[3] Massoud F, Chertkow H, Whitehead V, Overbury O, Bergman $\mathrm{H}$. Word-reading thresholds in Alzheimer disease and mild memory loss: A pilot study. Alzheimer Disease \& Associated Disorders. 2002; 16(1):31-9. [DOI:10.1097/00002093200201000-00005] [PMID]

[4] Petersen RC, Doody R, Kurz A, Mohs RC, Morris JC, Rabins $\mathrm{PV}$, et al. Current concepts in mild cognitive impairment. Archives of Neurology. 2001; 58(12):1985-92. [DOI:10.1001/ archneur.58.12.1985] [PMID]

[5] Ding D, Zhao Q, Guo Q, Meng H, Wang B, Luo J, et al. Prevalence of mild cognitive impairment in an urban community in China: A cross-sectional analysis of the Shanghai Aging Study. Alzheimer's \& Dementia. 2015; 11(3):300-9.e2. [DOI:10.1016/j.jalz.2013.11.002] [PMID]

[6] Petersen RC, Lopez O, Armstrong MJ, Getchius TS, Ganguli M, Gloss D, et al. Practice guideline update summary: Mild cognitive impairment: Report of the guideline development, dissemination, and implementation subcommittee of the american academy of neurology. Neurology. 2018; 90(3):12635. [DOI:10.1212/WNL.0000000000004826] [PMID] [PMCID]

[7] Tavares-Júnior JWL, De Souza ACC, Alves GS, de Carvalho Bonfadini J, Siqueira-Neto JI, Braga-Neto P. Cognitive assessment tools for screening older adults with low levels of education: A critical review. Frontiers in Psychiatry. 2019; 10:878. [DOI:10.3389/fpsyt.2019.00878] [PMID] [PMCID]

[8] Kosmidis MH, Bozikas VP, Vlahou CH, Kiosseoglou G, Giaglis G, Karavatos A. Verbal fluency in institutionalized patients with schizophrenia: Age-related performance decline Psychiatry Research. 2005; 134(3):233-40. [DOI:10.1016/j.psychres.2005.02.003] [PMID]

[9] Gliwa R. Verbal fluency in categories of common and proper names in the phase of mild cognitive impairment in the course of Parkinson's disease. Interdyscyplinarne Konteksty Pedagogiki Specjalnej. 2019; (27):249-72. [DOI:10.14746/ ikps.2019.27.12] 
[10] Nitrini R, Caramelli P, Bottino CMdC, Damasceno BP, Brucki SMD, Anghinah R. [Diagnosis of Alzheimer's disease in Brazil: cognitive and functional evaluation. Recommendations of the scientific department of cognitive neurology and aging of the brazilian academy of neurology (Portuguese)]. Arquivos de Neuro-psiquiatria. 2005; 63(3A):720-7. [DOI:10.1590/S0004-282X2005000400034] [PMID]

[11] Henry JD, Crawford JR, Phillips LH. Verbal fluency performance in dementia of the Alzheimer's type: A meta-analysis. Neuropsychologia. 2004; 42(9):1212-22. [DOI:10.1016/j.neuropsychologia.2004.02.001] [PMID]

[12] Vaughan RM, Coen RF, Kenny R, Lawlor BA. Semantic and phonemic verbal fluency discrepancy in mild cognitive impairment: Potential predictor of progression to Alzheimer's disease. Journal of the American Geriatrics Society. 2018; 66(4):755-9. [DOI:10.1111/jgs.15294] [PMID]

[13] Troyer AK. Normative data for clustering and switching on verbal fluency tasks. Journal of Clinical and Experimental Neuropsychology. 2000; 22(3):370-8. [DOI:10.1076/13803395(200006)22:3;1-V;FT370]

[14] Steiner VAG, Mansur LL, Brucki SMD, Nitrini R. Phonemic verbal fluency and age: A preliminary study. Dementia \& Neuropsychologia. 2008; 2(4):328-32. [DOI:10.1590/S198057642009DN20400017] [PMID] [PMCID]

[15] Senhorini MC, Amaro Júnior E, de Mello Ayres A, De Simone A, Busatto GF. Phonemic fluency in Portuguese-speaking subjects in Brazil: Ranking of letters. Journal of Clinical and Experimental Neuropsychology. 2006; 28(7):1191-200. [DOI:10.1080/13803390500350969] [PMID]

[16] Borkowski JG, Benton AL, Spreen O. Word fluency and brain damage. Neuropsychologia. 1967; 5(2):135-40. [DOI:10.1016/0028-3932(67)90015-2]

[17] Jordan LM. Verbal fluency: Norms for the Lakota population in semantic and phonemic fluency tasks [MSc. Thesis]. North Dakota: University of North Dakota; 2014. khttps:// commons.und.edu/theses/1669/

[18] Lanting S, Haugrud N, Crossley M. The effect of age and sex on clustering and switching during speeded verbal fluency tasks. Journal of the International Neuropsychological Society. 2009; 15(2):196-204. [DOI:10.1017/S1355617709090237] [PMID]

[19] Van Der Elst W, Van Boxtel MP, Van Breukelen GJ, Jolles J. Normative data for the Animal, Profession and Letter M Naming verbal fluency tests for Dutch speaking participants and the effects of age, education, and sex. Journal of the International Neuropsychological Society. 2006; 12(1):80-9. [DOI:10.1017/S1355617706060115] [PMID]

[20] Lubrini G, Periáñez JA, Laseca-Zaballa G, Bernabéu-Brotons E, Ríos-Lago M. Verbal Fluency Tasks: Influence of age, gender, and education and normative data for the Spanish native adult population. Archives of Clinical Neuropsychology. 2021; acab056. [DOI:10.1093/arclin/acab056] [PMID]

[21] Brucki S, Malheiros S, Okamoto I, Bertolucci P. [Normative data on the verbal fluency test in the animal category in our milieu (Portuguese)]. Arquivos de Neuro-Psiquiatria. 1997; 55(1):56-61. [DOI:10.1590/S0004-282X1997000100009] [PMID]

[22] Bialystok E, Craik FI, Luk G. Lexical access in bilinguals: Effects of vocabulary size and executive control. Journal of
Neurolinguistics. 2008; 21(6):522-38. [DOI:10.1016/j.jneuroling.2007.07.001]

[23] Luo L, Luk G, Bialystok E. Effect of language proficiency and executive control on verbal fluency performance in bilinguals. Cognition. 2010; 114(1):29-41. [DOI:10.1016/j.cognition.2009.08.014] [PMID]

[24] Paap KR, Myuz HA, Anders RT, Bockelman MF, Mikulinsky R, Sawi OM. No compelling evidence for a bilingual advantage in switching or that frequent language switching reduces switch cost. Journal of Cognitive Psychology. 2017; 29(2):89-112. [DOI:10.1080/20445911.2016.1248436]

[25] Sandoval TC, Gollan TH, Ferreira VS, Salmon DP. What causes the bilingual disadvantage in verbal fluency? The dual-task analogy. Bilingualism: Language and Cognition. 2010; 13(2):231-52. [DOI:10.1017/S1366728909990514]

[26] Ghoreishi ZS, Azimian M, Khorrami BA, Rafiee SM, Alaghband RJ, Salavati M, et al. [Lexical access in Persian normal speakers: Picture naming, Verbal fluency and Spontaneous speech (Persian)]. Iranian Rehabilitation Journal. 2014; 12(20):16-20. https://www.sid.ir/en/journal/ViewPaper. aspx?ID $=506138$

[27] Ebrahimipour M, Motamed MR, Ashayeri H, Modarresi Y, Kamali M. Developing the Persian version of the homophone meaning generation test. Medical Journal of the Islamic Republic of Iran. 2016; 30:335. [PMCID]

[28] Mohammadisabet V, Yadegari F, Foroughan M. [Verbal fluency performance in normal elderly Persian speakers (Persian)]. Iranian Journal of Ageing. 2016; 11(2):290-9. [DOI:10.21859/sija-1102290]

[29] Seyedian M, Falah M, Nourouzian M, Nejat S, Delavar A, Ghasemzadeh H. [Validity of the Farsi version of mini-mental state examination (Persian)]. Journal of Medical Council of I.R.I. 2008; 25(4):408-14. https://www.sid.ir/en/journal/ ViewPaper.aspx?id=133666

[30] Wahlund L-O, Barkhof F, Fazekas F, Bronge L, Augustin $\mathrm{M}$, Sjogren $\mathrm{M}$, et al. A new rating scale for age-related white matter changes applicable to MRI and CT. Stroke. 2001; 32(6):1318-22. [DOI:10.1161/01.STR.32.6.1318] [PMID]

[31] Scheltens P, Launer LJ, Barkhof F, Weinstein HC, van Gool WA. Visual assessment of medial temporal lobe atrophy on magnetic resonance imaging: Interobserver reliability. Journal of Neurology. 1995; 242(9):557-60. [DOI:10.1007/ BF00868807] [PMID]

[32] Ruff RM, Light RH, Parker SB, Levin HS. The psychological construct of word fluency. Brain and Language. 1997; 57(3):394-405. [DOI:10.1006/brln.1997.1755] [PMID]

[33] Machado TH, Fichman HC, Santos EL, Carvalho VA, Fialho PP, Koenig AM, et al. Normative data for healthy elderly on the phonemic verbal fluency task-FAS. Dementia \& Neuropsychologia. 2009; 3(1):55-60. [DOI:10.1590/S198057642009DN30100011] [PMID] [PMCID]

[34] Casals-Coll M, Sánchez-Benavides G, Quintana M, Manero R, Rognoni T, Calvo L, et al. Estudios normativos españoles en población adulta joven (proyecto NEURONORMA jóvenes): Normas para los test de fluencia verbal. Neurología. 2013; 28(1):33-40. [DOI:10.1016/j.nrl.2012.02.010] [PMID]

[35] Amieva H, Jacqmin-Gadda H, Orgogozo J-M, Le Carret N, Helmer C, Letenneur L, et al. The 9 year cognitive decline be- 
fore dementia of the Alzheimer type: A prospective population-based study. Brain. 2005; 128(5):1093-101. [DOI:10.1093/ brain/awh451] [PMID]

[36] Nutter-Upham KE, Saykin AJ, Rabin LA, Roth RM, Wishart HA, Pare N, et al. Verbal fluency performance in amnestic $\mathrm{MCI}$ and older adults with cognitive complaints. Archives of Clinical Neuropsychology. 2008; 23(3):229-41. [DOI:10.1016/j. acn.2008.01.005] [PMID] [PMCID]

[37] Gibbons LE, Carle AC, Mackin RS, Harvey D, Mukherjee $\mathrm{S}$, Insel $\mathrm{P}$, et al. A composite score for executive functioning, validated in Alzheimer's Disease Neuroimaging Initiative (ADNI) participants with baseline mild cognitive impairment. Brain Imaging and Behavior. 2012; 6(4):517-27. [DOI:10.1007/ s11682-012-9176-1] [PMID] [PMCID]

[38] Clark LJ, Gatz M, Zheng L, Chen Y-L, McCleary C, Mack WJ. Longitudinal verbal fluency in normal aging, preclinical, and prevalent Alzheimer's disease. American Journal of Alzheimer's Disease \& Other Dementias. 2009; 24(6):461-8. [DOI:10.1177/1533317509345154] [PMID] [PMCID]

[39] Mura T, Proust-Lima C, Jacqmin-Gadda H, Akbaraly T, Touchon J, Dubois B, et al. Measuring cognitive change in subjects with prodromal Alzheimer's disease. Journal of Neurology, Neurosurgery, and Psychiatry. 2014; 85(4):363-70. [DOI:10.1136/jnnp-2013-305078] [PMID] [PMCID]

[40] Mathuranath P, George A, Cherian P, Alexander Al, Sarma $S$, Sarma P. Effects of age, education and gender on verbal fluency. Journal of Clinical and Experimental Neuropsychology. 2003; 25(8):1057-64. [DOI:10.1076/jcen.25.8.1057.16736] [PMID]

[41] Gladsjo JA, Schuman CC, Evans JD, Peavy GM, Miller SW, Heaton RK. Norms for letter and category fluency: Demographic corrections for age, education, and ethnicity. Assessment. 1999; 6(2):147-78. [DOI:10.1177/1073191199006002 04] [PMID]

[42] Kavé G. Phonemic fluency, semantic fluency, and difference scores: Normative data for adult Hebrew speakers. Journal of Clinical and Experimental Neuropsychology. 2005; 27(6):690-9. [DOI:10.1080/13803390490918499] [PMID]

[43] Benito-Cuadrado M, Esteba-Castillo S, Böhm P, Cejudo-Bolivar J, Peña-Casanova J. Semantic verbal fluency of animals: A normative and predictive study in a Spanish population. Journal of Clinical and Experimental Neuropsychology. 2002; 24(8):1117-22. [DOI:10.1076/jcen.24.8.1117.8376] [PMID]

[44] Crossley M, D'arcy C, Rawson NS. Letter and category fluency in community-dwelling Canadian seniors: A comparison of normal participants to those with dementia of the Alzheimer or vascular type. Journal of Clinical and Experimental Neuropsychology. 1997; 19(1):52-62. [DOI:10.1080/01688639708403836] [PMID]

[45] Capitani E, Laiacona M, Basso A. Phonetically cued wordfluency, gender differences and aging: A reappraisal. Cortex. 1998; 34(5):779-83. [DOI:10.1016/S0010-9452(08)70781-0]

[46] Kawano N, Umegaki H, Suzuki Y, Yamamoto S, Mogi N, Iguchi A. Effects of educational background on verbal fluency task performance in older adults with Alzheimer's disease and mild cognitive impairment. International Psychogeriatrics. 2010; 22(6):995-1002. [DOI:10.1017/S1041610210000839] [PMID]

[47] Costa A, Bagoj E, Monaco M, Zabberoni S, De Rosa S, Papantonio AM, et al. Standardization and normative data obtained in the Italian population for a new verbal fluency instrument, the phonemic/semantic alternate fluency test. Neurological Sciences. 2014; 35(3):365-72. [DOI:10.1007/ s10072-013-1520-8] [PMID]

[48] Peña-Casanova J, Quiñones-Úbeda S, Quintana-Aparicio M, Aguilar M, Badenes D, Molinuevo JL, et al. Spanish multicenter normative studies (NEURONORMA Project): Norms for verbal span, visuospatial span, letter and number sequencing, trail making test, and symbol digit modalities test. Archives of Clinical Neuropsychology. 2009; 24(4):321-41. [DOI:10.1093/arclin/acp038]

[49] Portocarrero JS, Burright RG, Donovick PJ. Vocabulary and verbal fluency of bilingual and monolingual college students. Archives of Clinical Neuropsychology. 2007; 22(3):415-22. [DOI:10.1016/j.acn.2007.01.015] [PMID]

[50] Rosselli M, Ardila A, Araujo K, Weekes VA, Caracciolo V, Padilla M, et al. Verbal fluency and repetition skills in healthy older Spanish-English bilinguals. Applied Neuropsychology. 2000; 7(1):17-24. [DOI:10.1207/S15324826AN0701_3] [PMID]

[51] Rosselli M, Ardila A, Salvatierra J, Marquez M, LUIS M, Weekes VA. A cross-linguistic comparison of verbal fluency tests. International Journal of Neuroscience. 2002; 112(6):759-76. [DOI:10.1080/00207450290025752] [PMID]

[52] Gollan TH, Montoya RI, Werner GA. Semantic and letter fluency in Spanish-English bilinguals. Neuropsychology. 2002; 16(4):562-76. [DOI:10.1037/0894-4105.16.4.562] [PMID]

[53] McDonnell M, Dill L, Panos S, Amano S, Brown W, Giurgius $S$, et al. Verbal fluency as a screening tool for mild cognitive impairment. International Psychogeriatrics. 2020; 32(9):1055-62. [DOI:10.1017/S1041610219000644] [PMID]

[54] Nejad AM, Qaracholloo M. Frequency System of Phonemes: Contrastive analysis of common standard persian and English consonants in context-based corpora. Asian Social Science. 2013; 9(3):76-90. [DOI:10.5539/ass.v9n3p76] 
This Page Intentionally Left Blank 